\title{
Leaf spots on the prairies
}

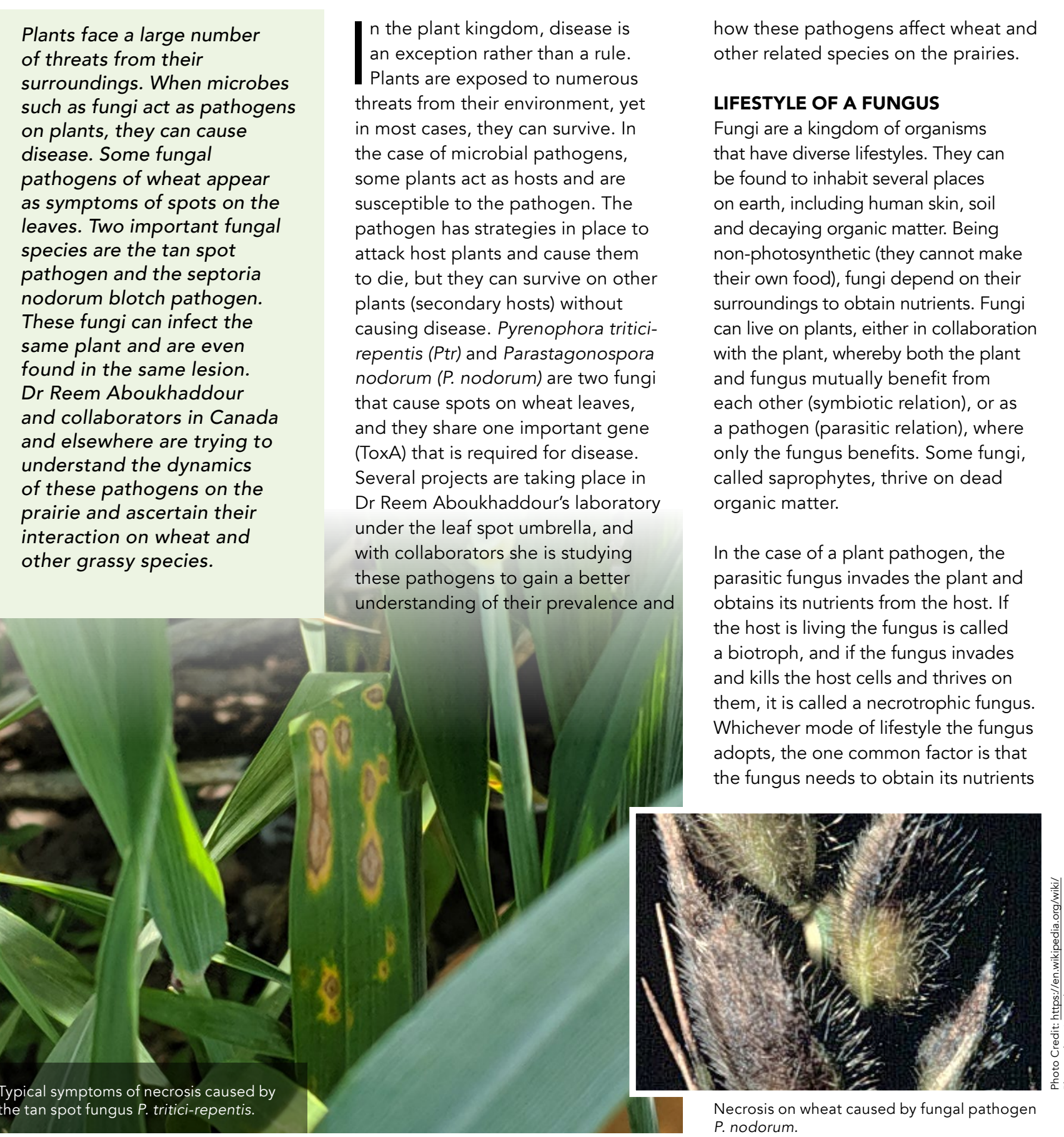

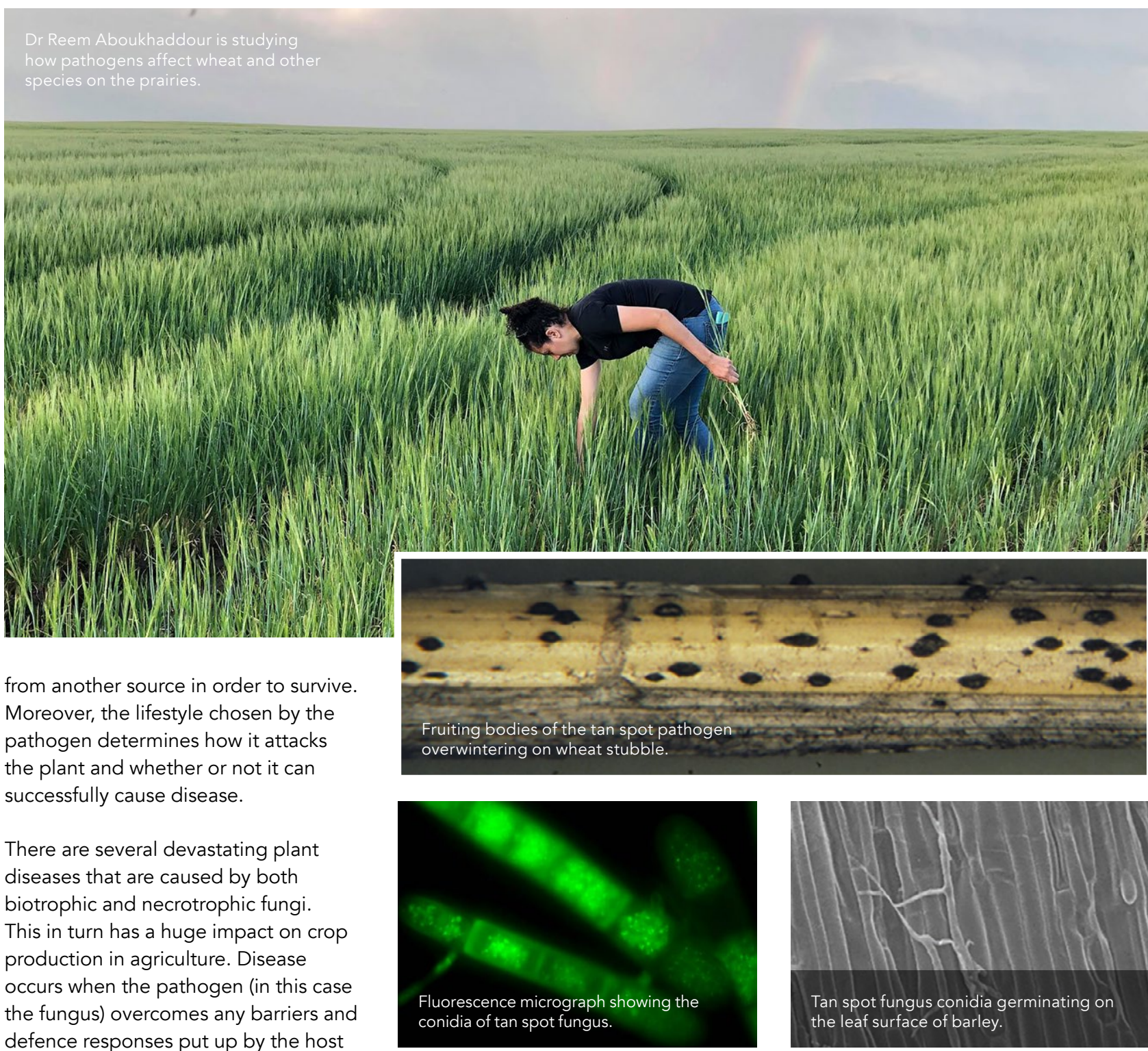

defence responses put up by the host plant, thereby infiltrating host tissues and causing cell death. In the case of produces small proteins pat mogen - called necrotrophic effectors - that can alter the structure and function of host cells. These necrotrophic effectors, previously known as host-specific toxins (HSTs), are toxic only to certain genotypes of the host plant. This mode of action is present in the tan spot (Ptr) and septoria nodorum blotch (P. nodorum) pathogens.

\section{MODE OF ATTACK}

Ptr and P. nodorum are destructive necrotrophs that have a wide host range of cereal and non-cereal grasses. These fungi, upon contact with the wheat host, secrete vario
combinations of necrotrophic effectors; each effector needs to

ToxA is a major virulence gene affecting wheat and has evolved differently in different species/locations. interact with its corresponding
receptor in the plant to cause a disease. These receptors are proteins that are usually encoded by dominant plant susceptibility genes. This explains why these fungi are specific in their action and cause diseases in certain wheat varieties that carry these matching susceptibility genes but cause no damage to plants lacking these genes. The ability of these fungi to secrete combinations of different effectors vary by the different races (varieties of the fungus)
geographical locations.
In a recent collaborative project, $\mathrm{Dr}$ new necrotrophic effector is widespread in Ptr populations in Tunisia. They are currently working on identifying this effector at the molecular level (Kamel et al., 2019). In North America and Australia, ToxA is the major necrotrophic effector, and is of particular importance because most North American wheat and $P$. nodorum as well as other leaf spotting pathogens produce it. The team sboukhaddour and colleagues have varietes are sensitive to ToxA. Both Ptr 


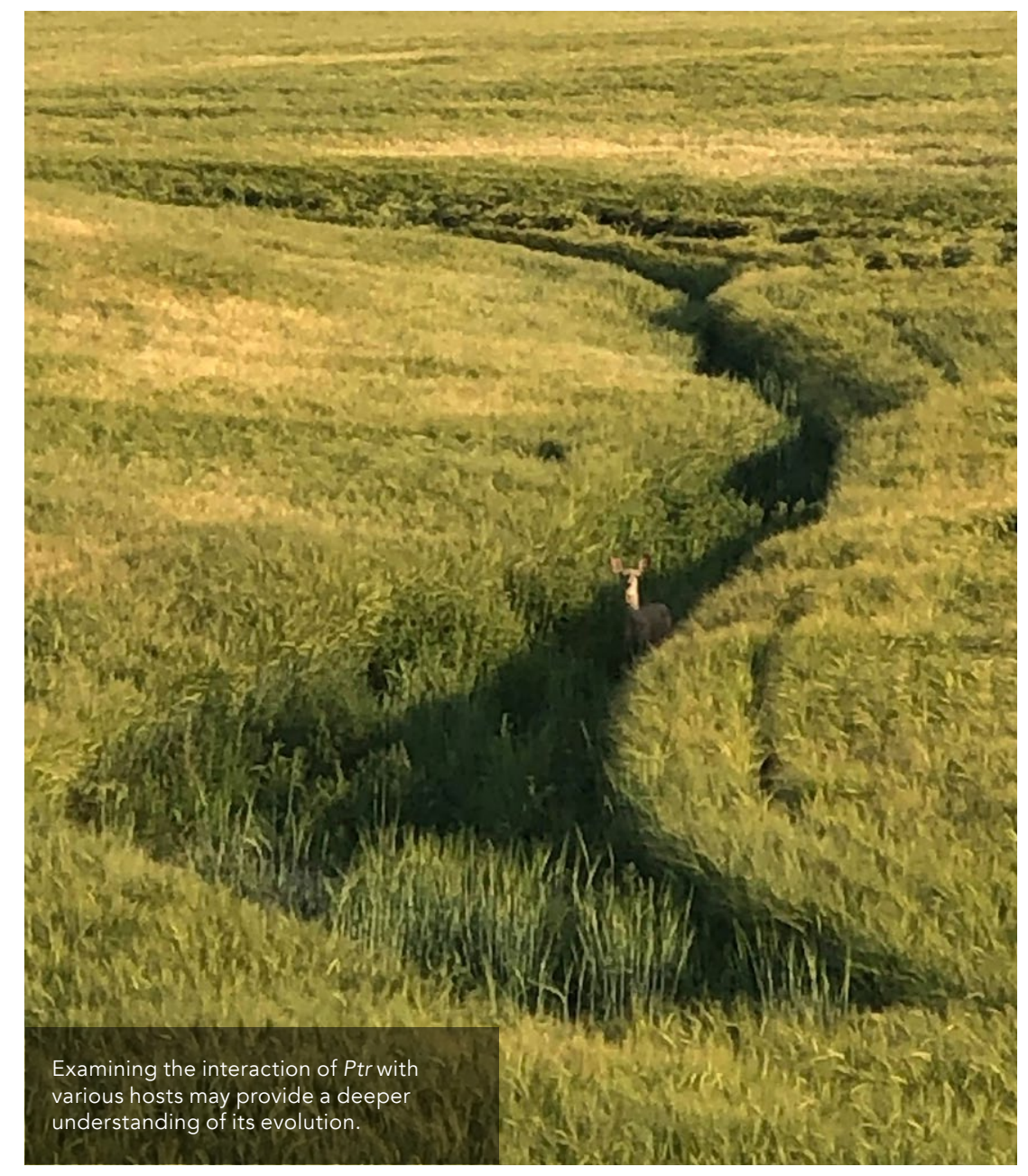

Ptr can cause mild symptoms on certain barley genotypes, but the ability of Ptr to grow without causing symptoms on resistant barley may reflect various levels of adaptability versus pathogenicity.

secreted by P. nodorum in Canada and Therefore, by investigating the different studied the prevalence of sensitivity studied the prevalence of sensitivity This is to help guide plant breeders spot producing pathogens, the scientists This is to help guide plant breeders reported on the relationship between the towards the pathogen. ToxA is a major virulence effector affecting wheat, and various haplotypes at a global level to predict the evolution of such important
virulence effector in various species/ locations (Hafez et al., 2020).
BARELY DAMAGED BARLEY

Ptr as a fungus on the prairies interacts examining its interaction with various hosts may provide understanding of the evolution of this pathogen, which can help us manage it. Little is known about how these fun interact with their secondary hosts, such as barley. In recently published work, Dr Aboukhaddour and colleagues examined the interaction of Ptr races with different varieties of barley. The authors found that Ptr races caused mild yellowing of leaves on certain genotypes, but not on others, and this was caused by ToxB, another protein effector produced by certain Ptr races Aboukhaddour and Strelkov, 2016). The symptoms on susceptible barley leaves where suggesting thas the observed chion, sugesting that the mode of both hosts. They also found that a single gene location in barley determined the susceptibility to Ptr, but the exact identity or nature of the gene involved needs further investigation (Wei et 2020). At a cellular level, it appeared that Ptr infected barley in a similar manner as it does in wheat. However, unlike wheat where the fungus cannot colonise resistant genotypes, the fungus on barley could grow further in resistant barley genotypes without showing symptoms, and only causing mild symptoms in susceptible genotypes. The ability of Ptr to grow without causing symptoms on resis wh bantey may reflect pathogenicity. pathogenicity

Given that pathogens are at a constant battle with crops, the challenge is to identify the scope of a potential pathogen to infect different crops at a global level. This will enable breeders to develop crops resistant to varieties the battle.

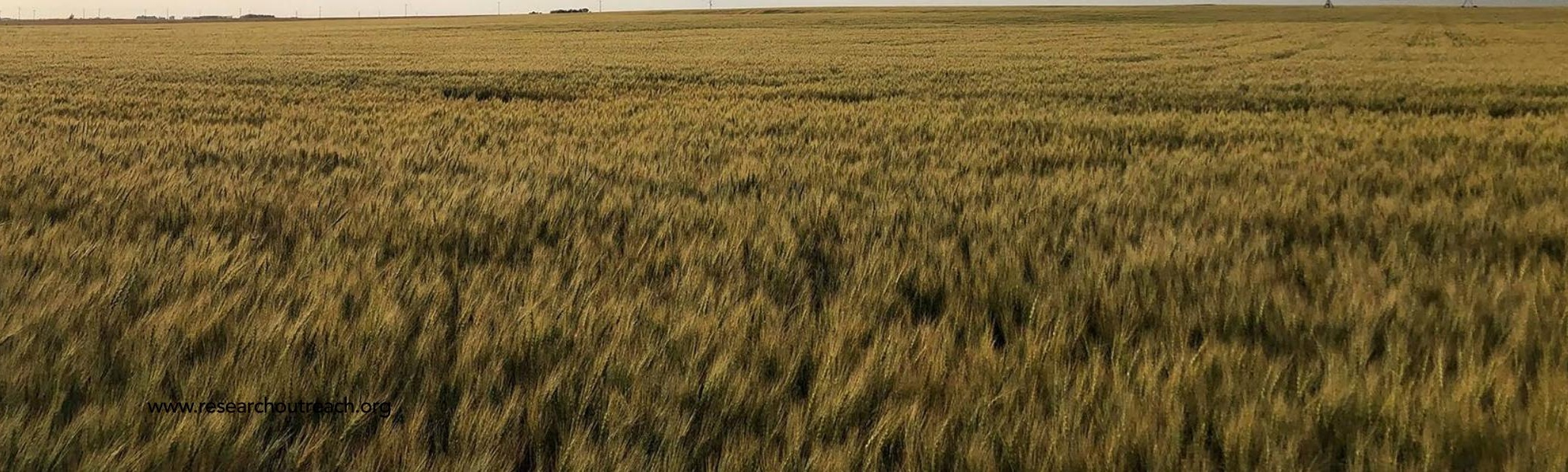

E: reem.aboukhaddour@canada.ca T: +1 403-317-2222

W: https://profils-profiles.science.gc.ca/en/profile/dr-reem-aboukhaddour

Research Objectives

Dr Aboukhaddour examines Pyrenophora tritici-repentis (Ptr), a destructive fungal pathogen of wheat.

\section{Detail}

Bio

Dr Reem Aboukhaddour obtained a master's degree from Wagening University in the Netherlands Manitoba, Canada She has been a postdoctoral fellow and resen associate at University of Alberta and is currently a research scientis at $A A F C$, focusing on cereal fungal pathogens.

Funding

- Agriculture and Agri-Food Canada

- Saskatchewan wheat commission

- Alberta Agriculture and Forestry - Alberta wheat commission

\section{Collaborators} - U.S. Department of Agriculture,

University of Alberta, Canada - The Sainsbury Laboratory, UK - Okayama University, Japan

\section{References}

Aboukhaddour, R. and Strelkov, R.E. (2016). Exploring de novo specificity: the Pyrenophora tritici-repentes-barley interaction. Plant Pathology, 65, 1347-1357. Available at: https://doi.org/10.1111/ppa.12500

Hafez, M., Gourlie, R., Despins, T., Turkington, T.K., Friesen, T.L., and Aboukhaddour, R. (2020). Parastagonospora nodorum and related species in Western Canada: genetic variability and effector genes. htop://doiog/10.1094/PHYTO-05-20-0207-R

Kamel, S., Cherif, M., Hafez, M., Despins, T., and Aboukhaddour. R. (2019). Pyrenophora tritici, and in Tunisia: race structure and effector genes. Frontiers in Plant Science, 10, 1562. Available at: https:///doi. org/10.3389/fpls.2019.01562

Tran, V., Aboukhaddour, R., Strelkov, I.S., Bouras, N. Spaner, D., and Strelkov, S.E. (2017). The sensitivity of Canadian wheat genotypes to Pyrenophora triticirepentes. Canadian Journal of Plant Pathology, 39(2), 149-162. Available at: https://doi.org/10.1080/07060661 .2017 .1339125

Wei, B., Moscou, M.J., Sato, K., Gourlie, R., Strelkov, S., and Aboukhaddour, R. (2020). Identification of a locus conferring dominant susceptibility to Pyrenophora triticiAvailable at: https://doi.org/10.3389/fpls.2020.00158

\section{Personal Response}

\section{What inspired you to conduct this research?}

I/ During the past 100 years, we have witnessed the by necrotrophs. These pathogens were either weaker pathogens on wild relatives or species that were not even known to cause any disease. Then, all of a sudden, the pathogens caused epidemics on several crops, as a result of wide adoption of a new genotype to which its sensitivity to necrotrophic effectors was unknown, or
because of the ability of a fungus like in Ptrto acquire a gene for virulence from other fungal species by asexual means of horizontal gene transfer. In all scenarios, the wide adoption of one type of crop on large area has facilitated selection pressure for these pathogens on the
same niche to share the same virulence genes. Therefore global surveillance for pathogens in local environments on crops and on other secondary hosts and exploring the pathogen ability to interact with these hosts are of importance. Once we understand the pathogen better, we can effectively eliminate susceptibility from our crops to achieve durable resistance. Other practices such as
diversifying rotations will also help mitigate leaf spot diseases' negative impact.

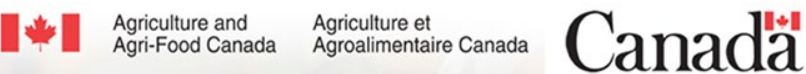

